Proc. Estonian Acad. Sci. Geol., 2001, 50, 4, 214-232

\title{
ADVANCES IN THE LUMINESCENCE DATING: THE OPTICALLY STIMULATED LUMINESCENCE BASED PROCEDURES AND THEIR PHYSICAL BACKGROUND
}

\author{
Galina HÜTT and Ivar JAEK \\ Institute of Geology, Tallinn Technical University, Estonia pst. 7, 10143 Tallinn, Estonia; \\ galinap@physic.ut.ee \\ Received 7 March 2001, in revised form 14 August 2001

\begin{abstract}
A review of the achievements made during the last decade in the study of the energy accumulation and transformation processes in quartz and alkali feldspars, used as natural palaeodosimeters, is given. It is shown how the obtained results have contributed to the application of optical dating through the use of alkali feldspars, finding more effective spectral regions of stimulation, and choice of optimal powers and duration of the stimulating impulses. The strong and weak points of the measuring procedures used in optical dating are analysed and the corresponding new highsensitivity apparatus is introduced. It appears that, in the case of a reasonable choice of the parameters of stimulating impulses, the presently used multiple-aliquots method is in every way competitive with the new methods.
\end{abstract}

Key words: natural palaeodosimeters, optically stimulated luminescence, dating procedure.

\section{INTRODUCTION}

Background ionization, caused by the radiation decay of the natural environmental isotopes ( $\mathrm{U}$, Th with daughters, and $\mathrm{K}$ ) and cosmic radiation, generates free electrons and holes in the crystal lattice of natural minerals. Some of these charge carriers can be trapped at structural defects or impurities and then be saved for a rather long time, comparable with the time span of the whole Quaternary. The number of saved charge carriers is a one-valued function of the radiation dose absorbed by the mineral.

Trapped electrons and holes can be released using laboratory methods. Also, the corresponding luminescence signal can be measured, which allows us to define the absorbed dose. In this connection minerals with good dosimetrical properties, like quartz and feldspars extracted from sediments and ancient 
ceramic, are widely used as palaeodosimeters in luminescence dating. The events being dated are the time of the last heating of ancient ceramic objects or the last exposure of sediments to light.

The informative luminescence signal can be produced in two ways. The thermoluminescence (TL) is produced during the heating of minerals, whereas the optically stimulated luminescence (OSL) is detected during their exposure to light at any fixed wavelength. Hence, there exist TL and OSL dating techniques. Huntley et al. (1985) were the first to use the OSL method for the dating of sediments. This method is more sensitive and effective, especially for the dating of sediments, and has thus largely developed during the last decade.

The present paper gives an overview of the progress in the field of palaeodosimetry. It concerns mostly the OSL dating technique including the basic studies, apparatus, and dating methods.

\section{BASIC STUDIES}

Luminescence dating techniques are not based on a strict law like the law of radioactive decay (decay of ${ }^{14} \mathrm{C}$, for example). This necessitates a basic physical study of the processes of energy accumulation and transformation in minerals, so that the techniques could be improved and effectively applied.

\section{The OSL stimulation spectra}

The study of the efficiency of (optical) response by stimulation means the measurements of the OSL stimulation spectra of quartz and alkali feldspars in the widest possible spectral region. Measuring the stimulation spectra in the short wavelength region of the spectrum has two spectral limitations: firstly, the overlap of the stimulation spectra in this region by emission spectra (see Fig. 1) and, secondly, the start of the optical ionization of luminescence centres causing the formation of an additional population in the dosimetric traps.

The first OSL stimulation spectra for alkali feldspars were obtained by Hütt et al. (1988). Later, the studies of the OSL stimulation spectra of alkali feldspars were carried out by Bailiff (1993), Bailiff \& Barnett (1994), Clark \& Sanderson (1994), Godfrey-Smith \& Cada (1996). The main stimulation band in these spectra is the infrared band in the region of $860-880 \mathrm{~nm}$. Bøtter-Jensen et al. (1994) and Huntley et al. (1996) were the first to obtain stimulation spectra for quartz. However, all these OSL measurements were limited because of the overlap of the stimulating light at $\sim 400 \mathrm{~nm}$ by the emission spectrum. This limitation was overcome by making use of the optically stimulated afterglow (OSA) as the informative signal (Hütt et al. 1999). This method makes it possible to expand the spectral range of OSL spectra measurements from $1100 \mathrm{~nm}$ to $250 \mathrm{~nm}$ (Fig. 1). 


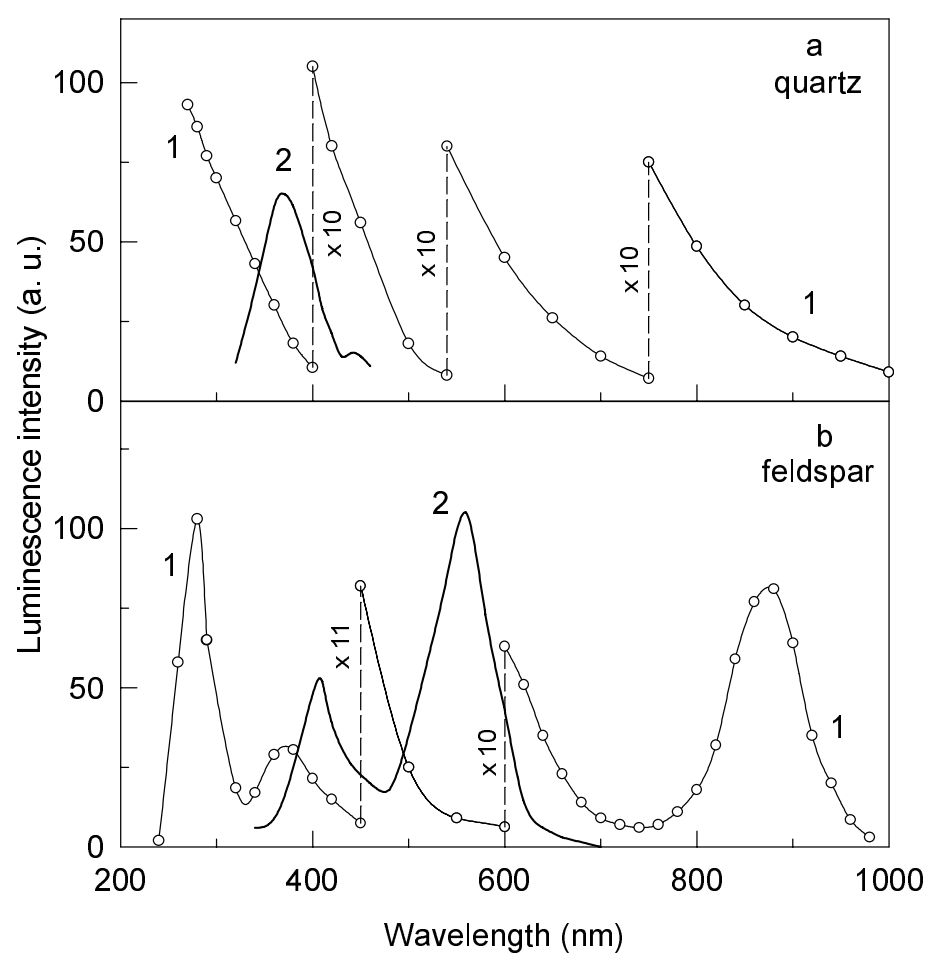

Fig. 1. (a) The OSA stimulation spectrum of natural quartz, extracted from sediments (curve 1) and spectral composition of the OSL emission during stimulation at $1.92 \mathrm{eV}$ (curve 2 from Huntley et al. 1996). (b) The OSA stimulation spectrum of alkali feldspars, extracted from sediments (curve 1) and spectral composition of the OSL response during IR stimulation (curve 2). Luminescence intensity is given in arbitrary units (a. u.) (from Hütt \& Jaek 2000).

\section{Characteristics of traps}

The OSL signal can be measured during the short stimulation pulses which practically do not change the population of traps, or as the whole decay curve of the OSL (up to minimal signal intensities). Different parts of this decay curve are used for dating, including the initial signal, OSL light sum, etc. However, several factors, such as temperature, duration of illumination, the wavelength or intensity of the stimulation light, influence the shape of the OSL decay curve. These factors have been studied in detail by, e.g., McKeever et al. (1997) and Murray \& Wintle (1998). The decay curve can usually be fit as a sum of exponential components. In any case, there exist the so-called quick components and slow components with some residue (see Fig. 2).

Different measurement conditions have brought about various ways for fitting the decay curves. These are discussed in the following publications. 


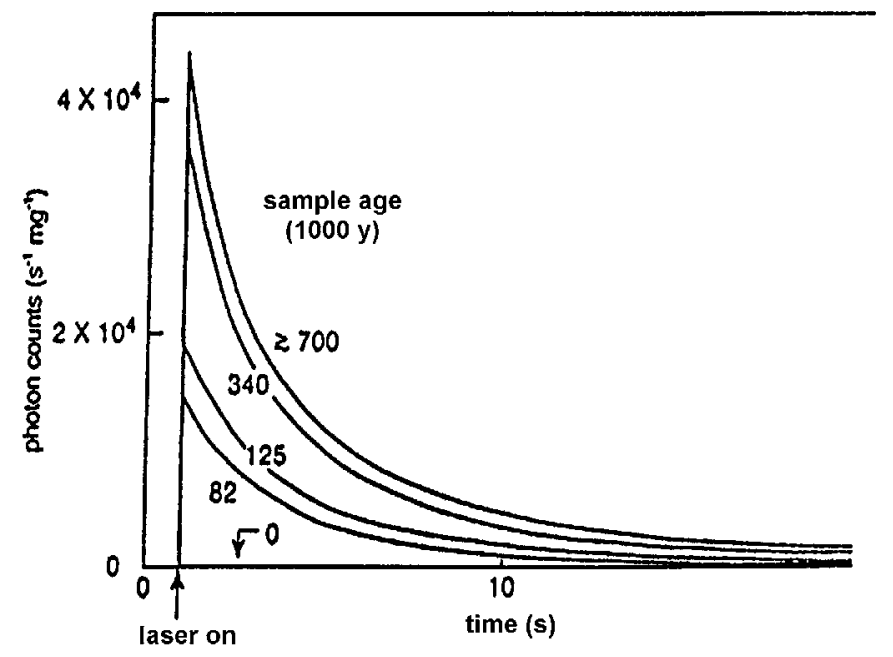

Fig. 2. Luminescence vs. time curves for similar quartz samples of different ages. Stimulation about $50 \mathrm{~mW} / \mathrm{cm}^{2}$ of $2.4 \mathrm{eV}$ photons (from Huntley et al. 1996).

Smith \& Rhodes (1994) fit the green-stimulated OSL decay in quartz at $110^{\circ} \mathrm{C}$ with three exponents (exponential functions). Spooner (1994) and Bailey et al. (1997) suppose that the change in the OSL decay curves after partial bleaching and irradiation (OSL measured at $160^{\circ} \mathrm{C}$ ) can be understood in terms of the model of three spectral components with different growth characteristics and optical stabilities. Basing on this observation, Bailey (2000) claims that the use of the so-called shine plateau in assessing the history of bleaching of sediments is limited.

Huntley et al. (1996) suggest that different traps with different optical ionization cross-sections are responsible for the OSL "full" decay curve. Traps with a larger cross-section of ionization are dominating in the initial phase of luminescence during the stimulation. These traps are essential for dating because they are the most sensitive to light and can be bleached better in natural conditions. Consequently, using short pulses ( $\geq 3 \mathrm{~s}$ ) of stimulation, we are able to select traps that can be bleached more completely, and this is an advantage of the OSL technique.

Bulur (1996) recommended an alternative technique for the OSL experiment. The idea of this technique is to detect the OSL signal while linearly increasing the intensity of the stimulating light. The power of the light source of stimulation changes from 0 to $20 \mathrm{~mW} / \mathrm{cm}^{2}$. By doing so the peak-shaped OSL decay curve is obtained instead of the decay curve obtained by using the traditional method constant intensity of stimulating light. Bulur \& Göksu (1999) and Bulur et al. (2000) measured the OSL from feldspars using the IR stimulation and linear modulation technique. 
The peak-shaped OSL decay of quartz is shown in Fig. 3. Bulur et al. (2000) assumed that four kinds of traps are responsible for this OSL decay curve: peaks $\mathrm{A}$ and $\mathrm{B}$ are caused by the quick components - easily bleachable traps, C and D are the slow components. Furthermore, they obtained evidence from experiments showing that the components have different thermal stability and different levels of saturation. Namely the slow components $(C, D)$ have a higher level of saturation and relatively high thermal stability.

Other authors (Dietlefsen \& Huntley 1994; Spooner 1994; Duller \& BøtterJensen 1996; Alexander et al. 1997), using the same stimulation, set forth an idea of the existence of one kind of trap responsible for the OSL decay curve. This hypothesis is supported by pulse annealing of the OSL signal in quartz and alkali feldspars (Fig. 4), where traps of one kind are responsible for the TL dosimetric peak and OSL signals in the whole spectral region of stimulation (Hütt \& Jaek 2000). There might not be a disagreement between the two viewpoints discussed above, as in the case of only one type of centre and strictly first kinetics (which apparently is not realized in practice) the decay curve is not describable as one exponent. It is caused by additional processes like retrapping, competition, nonradiative recombination processes, etc. taking place in a real crystal. As we know, every nonexponential decay curve can be described as the sum of exponent functions.

The views concerning the problem of how many kinds of traps are responsible for the OSL response can be summarized as follows. Using the weak (up to $\left.4 \mathrm{~mW} / \mathrm{cm}^{2}\right)$ and short pulses of stimulation $(\leq 3 \mathrm{~s})$ sensitive traps of one kind are revealed which are also responsible for the TL dosimetric peak in quartz $\left(325^{\circ} \mathrm{C}\right)$ and feldspars $\left(310^{\circ} \mathrm{C}\right)$. More prolonged and intensive stimulation reveals other

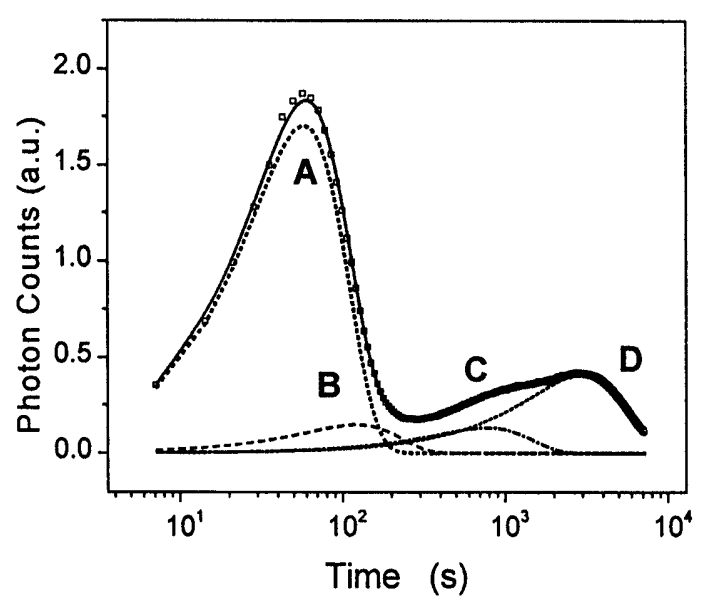

Fig. 3. Linear modulated optically stimulated luminescence (LM-OSL) curve from quartz. The various components (A, B, C, D) are obtained by curve fitting; OSL was measured at $160^{\circ} \mathrm{C}$ for $7200 \mathrm{~s}$ after preheating at $280^{\circ} \mathrm{C}$ for $10 \mathrm{~s}$ (from Bulur at al. 2000). 


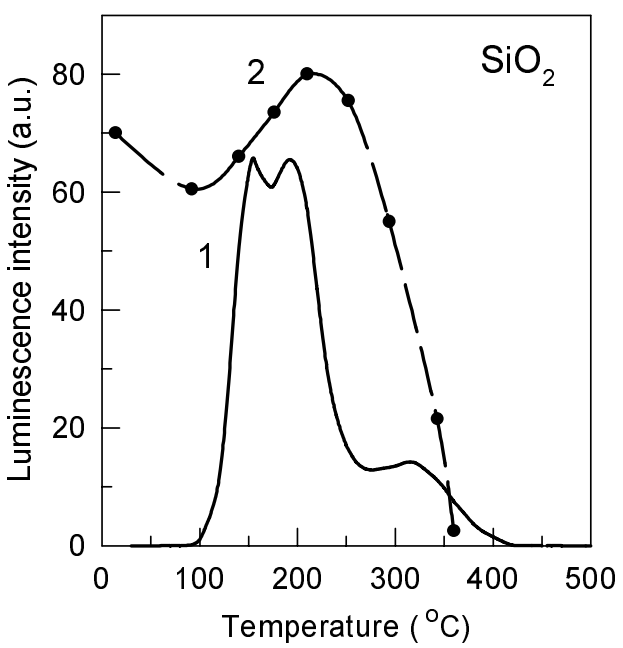

Fig. 4. Sensitized quartz after X-ray excitation at room temperature: 1, TL glow curve; 2 , thermooptical bleaching by stimulation at $450 \mathrm{~nm}$ (from Hütt \& Jaek 2000).

kinds of traps, less sensitive to light. However, the question of whether the corresponding traps have different microstructures can be answered through detailed spectral study. The relative concentration of the less light-sensitive centres compared to those more sensitive to light remains open as well.

\section{Models of the OSL processes in alkali feldspars and quartz}

The prevailing mechanism of the OSL processes in alkali feldspars by using the IR band of stimulation was proposed already more than ten years ago by Hütt et al. (1988) as thermooptical transition of electrons. Stimulation of this band transports the electrons from the ground state of deep traps to the excited level localized just under the bottom of the conduction band. Electrons transit from this level to the conduction band by thermal assistance, and this process is followed by irradiative recombination.

Studying the decay curve during prolonged stimulation, Bailiff \& Poolton (1991) and Bailiff \& Barnett (1994) found that the process of the IR stimulated OSL is more complicated. The decay curve was not monoexponential and was not entirely "frozen" at low temperature. Poolton et al. (1995) concluded from experiments that the IR stimulated OSL might be caused by the donor-acceptor recombination mechanism. The study of the spectral composition of secondary phosphorescence, however, did not reveal any changes in it during phosphorescence decay (G. Hütt, unpubl. data). In the case of pair recombination a shift of emission bands is expected. The component of IR stimulated OSL, not depending 
on temperature, is probably caused by tunnelling from the excited state of trap (Visosecas 1993; Visosecas et al. 1994); this effect is well known in alkali halide crystals. The described additional mechanisms are of little relevance in the usual dating conditions (temperature close to room temperature, stimulation density of a few $\mathrm{mW} / \mathrm{cm}^{2}$ ).

Using visible stimulation the thermal influence on the processes of deep traps ionization has also been revealed in the case of quartz and alkali feldspars. Spooner (1994) supposed that this effect in quartz is caused by thermal population of a set of narrowly spaced excited states near the ground state of the defect, from which optical stimulation brings charge carriers to the conduction band. Huntley et al. (1996) revealed that the intensity of the OSL depends on temperature when using stimulation from 1.84 to $2.73 \mathrm{eV}$ (see Fig. 5), whereas the energy of thermal activation, calculable from the dependence of OSL intensity on temperature, is also a function of the energy of stimulating photons. It has the highest value at small energies and becomes zero at $\sim 2.75 \mathrm{eV}$.

According to McKeever \& Chen (1997), electrons are not translated from the ground state to the conduction band straight but via delocalized states. The question of where these delocalized excited states are situated remains unanswered.

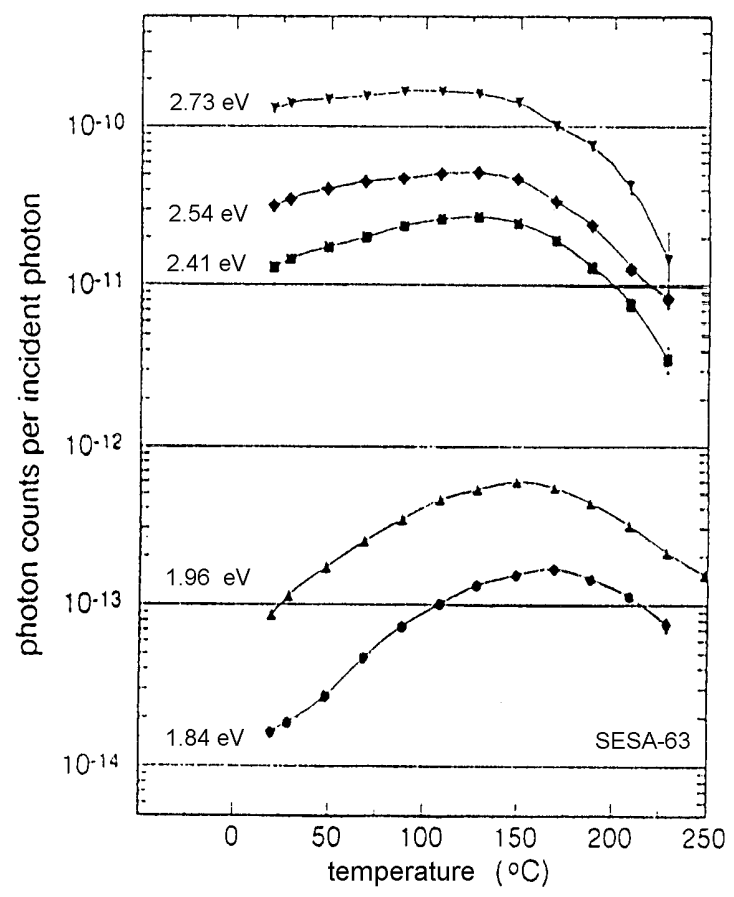

Fig. 5. Temperature dependence of the OSL of quartz during stimulation with various photons energies which are shown on the curves (from Huntley et al. 1996). 


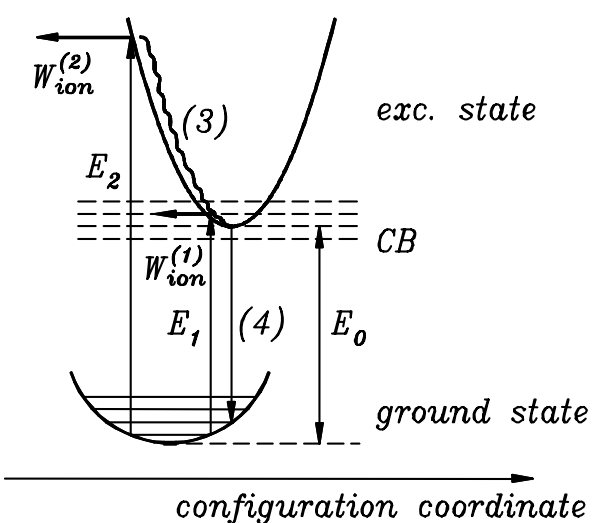

Fig. 6. Configuration coordinate diagram for ground and excited states at deep traps in quartz. $E_{0}$ is the difference in the energy (the distance) between the minimums of two potential curves; $E_{1}$ and $E_{2}$ are excitation quantum energies; $W_{\text {ion }}^{(1)}$ and $W_{\text {ion }}^{(2)}$ are probabilities of ionization of quasilocal state; (3) and (4) are two steps of transition from excited to ground state; CB is the conduction band (from Hütt et al. 2001).

In Hütt et al. (2001) we explained the photoionization of the deep traps in quartz and in the short-wave stimulation bands of alkali feldspars as transitions from the different vibrational levels of the ground state to quasilocal states, which are overlapped by the conduction band. In these states a greater probability of ionization (exponentially growing with energy) corresponds to the higher energies. A corresponding diagram of energy in configuration coordinates is presented in Fig. 6. This scheme explains the experimental results of Huntley et al. (1996) about the reliance of the energy of thermal activation on the stimulation wavelength. It also covers the hypothesis of Spooner (1994) that there are many ground states (a set of narrowly spaced excited states near the ground state).

\section{APPARATUS AND DATING METHODS}

Dating by the luminescence method includes at least three types of measurements:

1. Producing a dose-induced luminescence signal, separating it, and determining its magnitude (the light sum of TL, the initial intensity of the OSL or its light sum, for example).

2. Determining the dose sensitivity of the sample being dated (laboratory calibrating).

3. Determining the annual dose (measuring the dose rate). 
Estimation of the progenetic light sum (in some cases known as determination of the level of bleaching of the sample) and conventional procedures for separating the corresponding mineral-palaeodosimeter from the sediments or ceramics are added to these measurements.

The method for determining the dose absorbed by a luminescence dosimeter is first used to measure the luminescence induced by the unknown (natural in palaeodosimetry) dose, then to expose the dosimeter to different laboratory radiation doses, and finally to measure its luminescence to construct OSL intensity vs. laboratory dose. Ideally, the sensitivity of phosphor must not change from the unknown dose to the calibration dose. In retrospective dosimetry (includes all dating applications) it is impossible to find a sample of unaltered dosimeter that could be used to test whether the sensitivity has changed.

It was noticed long ago that changes in sensitivity by luminescence dating really occurred. Various measurement protocols have been developed to deal with this problem. These protocols can generally be divided into two groups (see, e.g., Wintle 1997; Aitken 1998):

1. Additive dose protocols - the laboratory dose is added to the existing unknown (natural) dose, and the unknown dose is then estimated by extrapolation.

2. Regenerative dose protocol - the "natural" luminescence signal is measured, the sample is entirely bleached and the dose response curve regenerated using laboratory doses. The unknown (natural) dose is then estimated by interpolation of the natural luminescence signal onto the regenerated curve.

All these protocols require the application of many samples, perhaps up to 100 aliquots per one estimate of the dose. Ideally, the luminescence characteristics of all aliquots would be identical, but these are not for many reasons. As a rule, single grains have greatly different luminescence characteristics, likewise, resetting (zeroing) the light-exposed sediments is almost definitely heterogeneous; only in some grains will the population of the trapped charge grow from zero. Obtaining more or less precise results is a labour-consuming process and needs a lot of material. To overcome the difficulties with the samples not being homogeneous, various single-aliquot protocols have been proposed (Murray 2000). Protocols of this kind seem to be especially promising for using the OSL as in this case it is possible to obtain the luminescence response (using short-time light impulses of low intensity) without considerably changing the population of the accumulated charge carriers. Doing so one can add the laboratory dose to the same aliquot after measuring the signal corresponding to the natural dose, and then measure the OSL signal which corresponds to the combination of the natural and the laboratory dose. By repeating this process the dose response curve can be obtained.

Unfortunately, datings obtained like that have turned out to be not precise enough and some additional procedures are needed. These additional procedures include preheating after treating the sample with a laboratory dose, or laboratory radiation at higher temperatures. The need for these thermal procedures appeared from the elementary analysis of the zone models of luminophores. It is already in the simpler models, containing traps of only one type (dosimetric traps) and 
recombination centres of one type (see, e.g., Hütt 1990) that the level of saturation starts to depend on the intensity of excitation (on the power of the dose) which is very different in the case of natural and laboratory radiation (correspondingly c. $0.001 \mathrm{~Gy} /$ year and $0.01 \mathrm{~Gy} / \mathrm{s}$ ). Real systems are always more complicated as they include several types of traps for electrons as well as for holes and, therefore, have several recombination canals. These models are characterized by two types of additional processes: (1) competition between different traps and recombination centres, depending on the density of excitation, and (2) the possibility of redistribution of charge carriers between the traps. This type of model for luminescence dosimeters has been analysed before (e.g., Jaek et al. 1974). McKeever \& Chen (1997) analysed this problem specially in connection with natural palaeodosimeters. The corresponding model is presented in Fig. 7. They came to the conclusion that the conditions of competitions can, at least partially (concerning shallow traps), be approximated by natural radiation and laboratory radiation at higher temperatures. In the latter case the population of charge carriers can be kept low, as it is with natural radiation. The redistribution of charge carriers, which simulates the corresponding process by natural radiation, can be brought about by preheating or by keeping the palaeodosimeter at room temperature for a long time after laboratory radiation and before measurements.

Yet, after these procedures a number of problems still remain unsolved: the sensitivity changes due to heating-cooling cycles even without additional doses (Wintle 2000); the conditions of competition of deep electron and hole levels cannot be much influenced by heating procedures. These conditions can and do

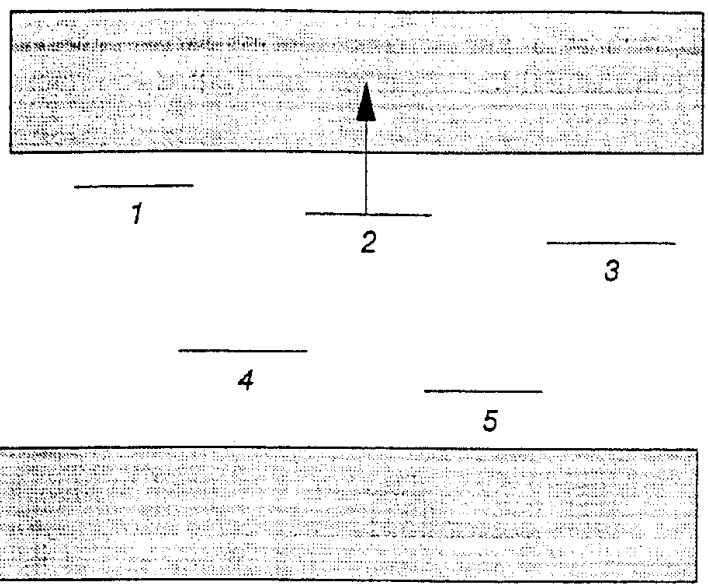

Fig. 7. Zone diagram model for phototransferred thermoluminescence and OSL, including an optically active trap (level 2), a deep competing trap (level 3), a shallow competing trap (level 1), a radiative recombination centre (level 4), and a nonradiative recombination centre (level 5) (from McKeever \& Chen 1997). 
depend on the density of excitation. Thus, protocols that would enable taking the above-mentioned causes of the sensitivity changes into account and obtaining corrected data, are needed. The change of sensitivity can be determined using additional samples and performing the corresponding heating-cooling cycle without applying any additional doses. That is what Duller (1991) did, but in his case it was not the single-aliquot protocol that was concerned, besides, all the possible changes of sensitivity were not taken into account. Thus the measuring procedure had to be improved so that all the changes of sensitivity would be considered and only one aliquot used (Duller 1995). This has been attempted for the additive as well as for the regenerative dose protocols. One possibility of taking account of sensitivity changes is based on the observation (Galloway 1996; Murray et al. 1997) that the decrease in the OSL signal during the heatingstimulating cycles is exponential; the decay rate does not depend on the added dose. It enables us to measure the decrease in the sensitivity after measuring the growth curve of the additive dose and thus to obtain a real procedure of one aliquot. Another possibility is based on the observation that in quartz the OSL signal and the $110^{\circ} \mathrm{C} \mathrm{TL}$ peak, arising after the laboratory dose, are proportional. The factor of proportionality once again does not depend on the dose. By experimentally determining the factor of proportionality for the given aliquot (using different laboratory doses) the size of the expected TL signal, corresponding to the natural OSL signal, and hence already the unknown natural dose can be determined. In doing so the test dose is chosen as similar to the value of the expected natural dose as possible. This procedure was proposed by Wintle \& Murray (1997). The current standard single-aliquot regenerative-dose protocol uses a number of different regenerative doses, one fixed test-dose in every cycle of measuring, and thermal treatments before measuring the OSL signal. Also, at times the already used values of regenerative dose are repeated in order to take the sensitivity change more precisely into account (see, e.g., Murray 2000; Murray \& Wintle 2000).

The specified variants of the regenerative dose protocols have been applied to feldspars, using both the IR and blue light stimulation, and excellent agreement between quartz and feldspar ages of the studied deposits has been detected (Chougaonkar 2000). Nevertheless, it has to be mentioned that in the case of feldspars difficulties are expected when applying protocols that are connected with all kinds of preheating as the emission spectrum of many feldspars changes already at moderate $\left(80^{\circ} \mathrm{C}, 353 \mathrm{~K}\right)$ heating (Fig. 8).

So far we have not mentioned the optimal preheating temperature and time (duration). It is clear that precise precepts for preheating and radiation at higher temperatures depend on the particular parameters of the above-mentioned model (Fig. 7). These parameters seem to vary on a wide scale even in the case of one mineral.

The views published on this subject disagree considerably. The best solution is direct experimental determination of the influence of different heatings, using ever higher temperatures and watching their influence on the results of dating 


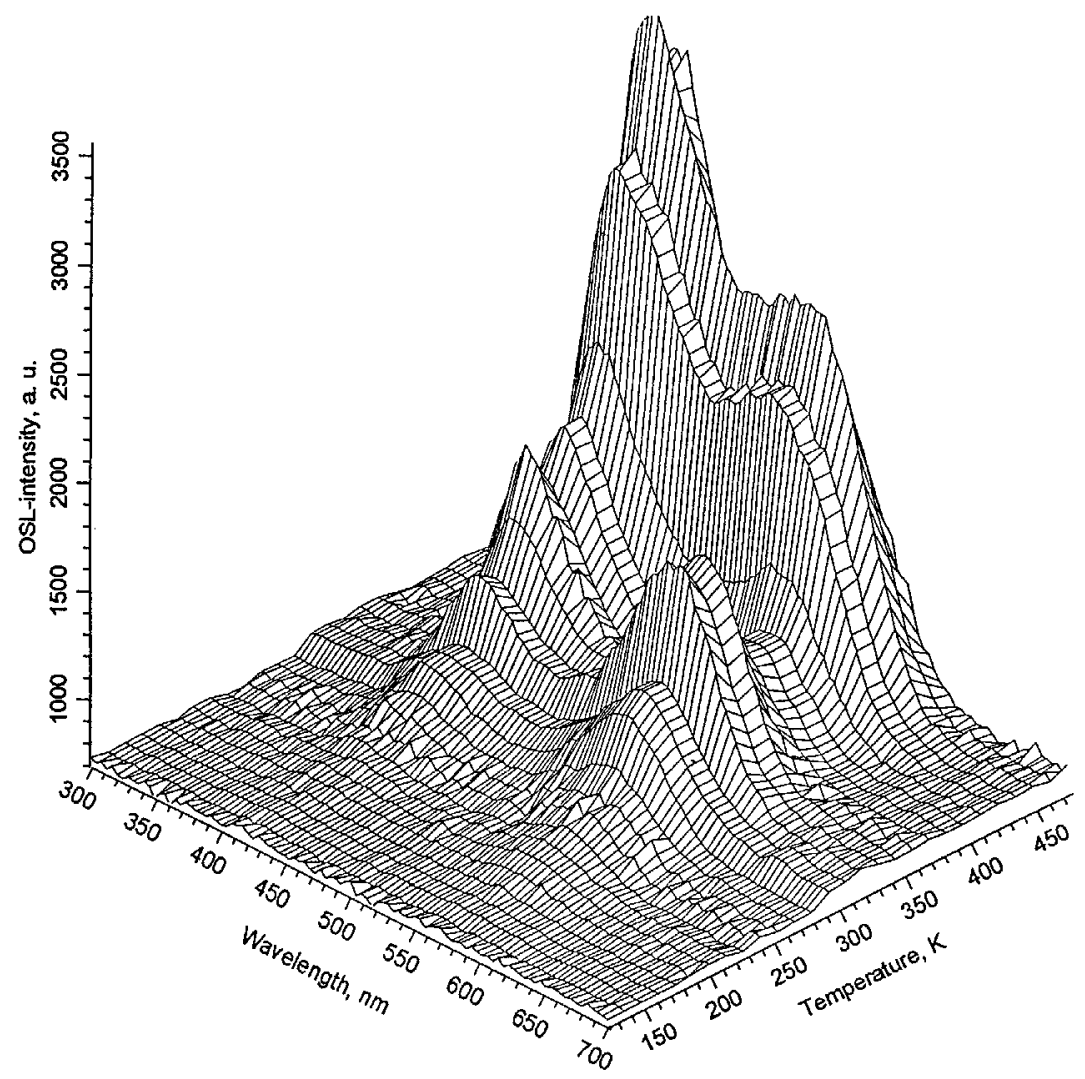

Fig. 8. Temperature dependence of IR stimulated OSL emission spectra of alkali feldspars extracted from sediments (from Rieser et al. 1997).

(the so-called preheat plateau test). Unfortunately, it has turned out that thermal treatments to different temperatures are necessary for samples of different ages.

In order to reduce the problems caused by heterogeneity of the samples, it would be natural to go over to measurements using a single grain, as it should basically be a homogeneous object. During the recent years there have been numerous tryouts of the options offered by the single-grain technique. These options have become available thanks to the great progress in experimental techniques (Markey et al. 1996; Bøtter-Jensen et al. 2000). The scheme of a reader of this kind, built in Risö, is presented in Fig. 9. This device enables measurements with constant intensity of stimulation as well as in the mode of linear modulation, and use of different sources of stimulation (different wavelengths, Bøtter-Jensen 2000).

Regenerative, as well as additive dose protocols, can be applied to a single grain. In this way the earlier qualitative observation has found quantitative proof 

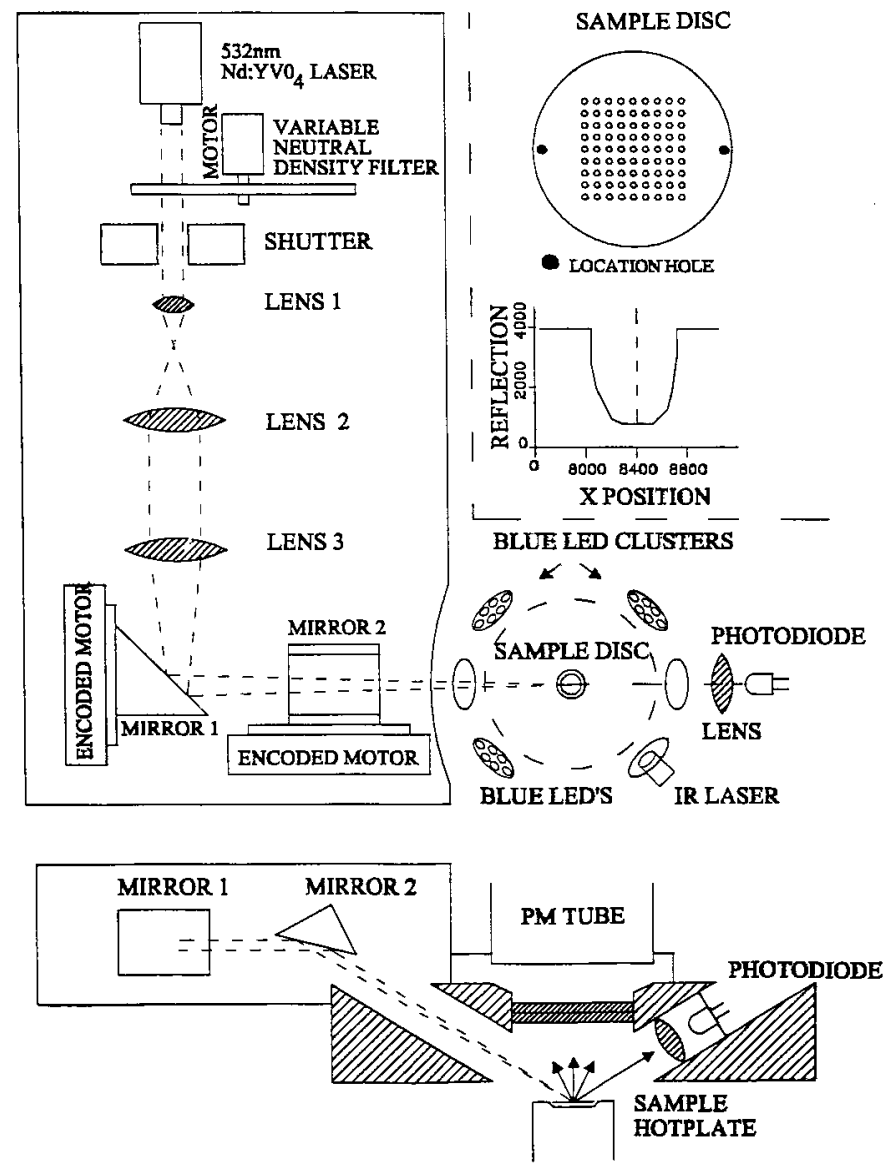

Fig. 9. Schematic diagram of the single-grain laser OSL unit. The sample disc and an example of a reflected locating hole profile are also shown. The diameter of the locating holes is $500 \mu \mathrm{m}$; the reflection is given in arbitrary units; 81 holes for grains are $300 \mu \mathrm{m}$ deep and $300 \mu \mathrm{m}$ in diameter with hole centres being $600 \mu \mathrm{m}$ apart. The beam from Nd:YVO laser is focused to a spot of $20 \mu \mathrm{m}$ in diameter, location precision better than $3 \mu \mathrm{m}$. Alternative stimulation sources are light emitting

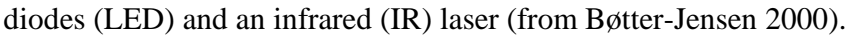

that different grains may have very different intensity of luminescence. For example, in some samples $95 \%$ of the light sum comes from $7 \%$ of the grains (Duller 2000). In that connection the accuracy of the absorbed dose determination is varying as well. The dose sensitivity of single grains is also varying on a large scale. It has turned out that different single grains may have been bleached very differently during sedimentation (Olley et al. 1999).

Thus, the determined dose of a single grain has to some extent a random size. In order to determine the real value of the dose, the results obtained from a great number of grains need to be statistically processed (see Fig. 10). 


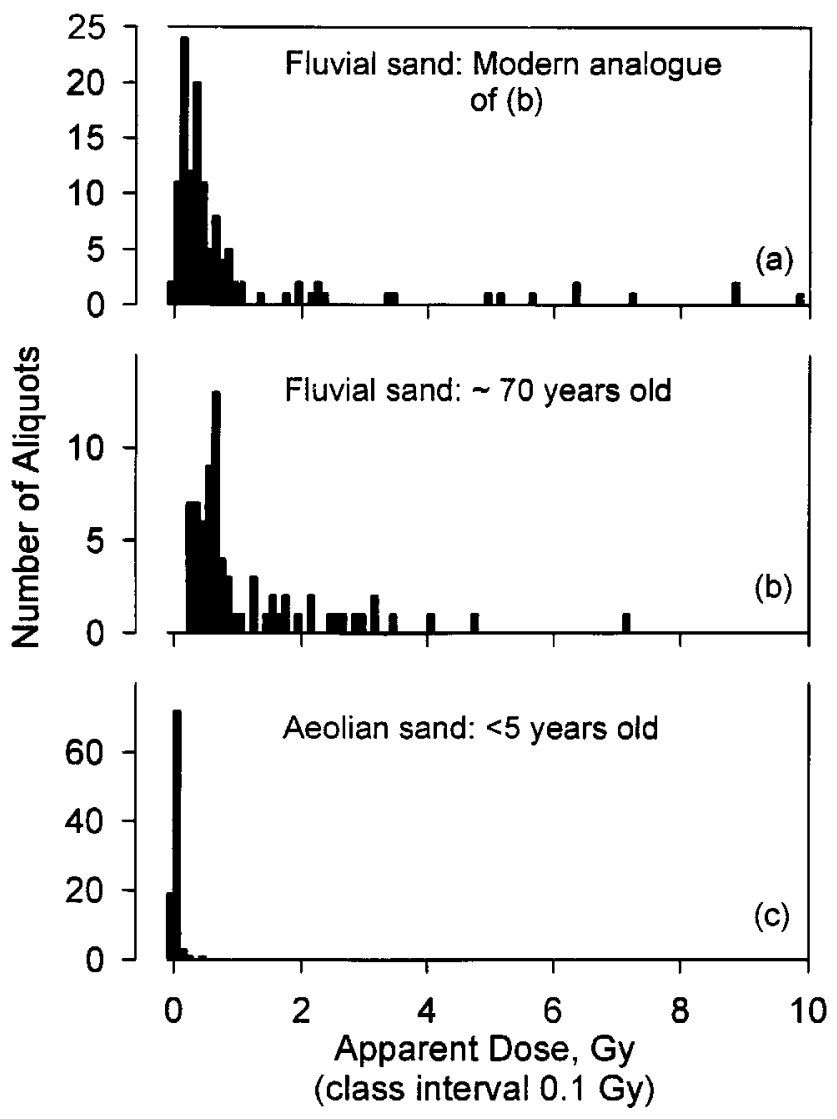

Fig. 10. Dose distribution (single-aliquot protocol) in known age sediments (from Murray \& Olley 1999).

Murray \& Roberts (1997) concluded that the considerable scattering in the natural doses probably arose because of variations in microdosimetry. Depending on the closest neighbourhood of the grain in the deposit (content of other minerals in the range of a few millimetres from the grain), the dose may differ by $\pm 75 \%$ from the average of the sample.

The above shows that in any case a great number of grains are to be measured in order to determine the age of a deposit. In this respect the single-grain method does not save working hours in dating. Nevertheless, statistical analysis of the measurement results of one deposit enables determination of the reason for the scattering of the results: mixing of different layers, different levels of resetting of the grains, variations in microdosimetry, etc. (Duller 2000). All these factors undoubtedly need detailed analysis. For example, in connection with the problem 


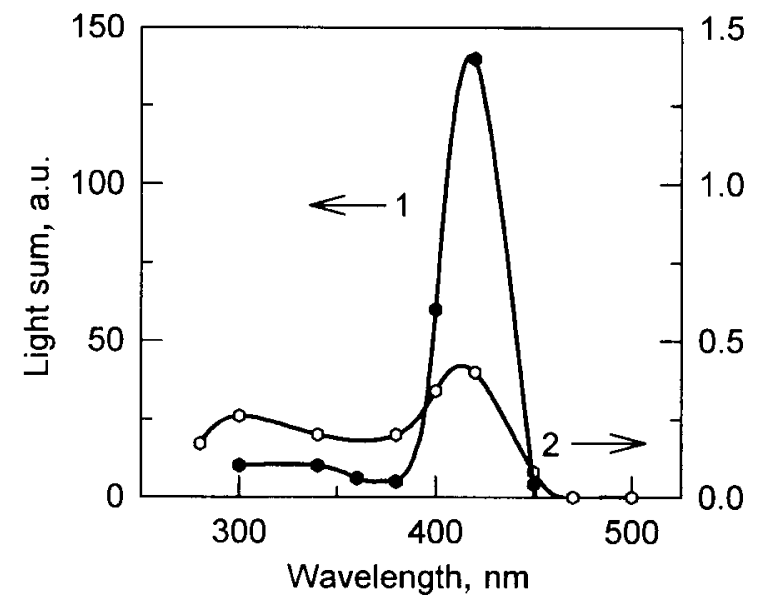

Fig. 11. The "action" spectra of alkali feldspars for two samples from different deposits (samples 1 and 2). The "action" - balance result of the excitation of recombination luminescence and bleaching. Light sum in the span $20-350^{\circ} \mathrm{C}$ vs. the excitation wavelength. Every sample was heated to $450^{\circ} \mathrm{C}$ before each excitation, $t_{\mathrm{exc}}=10 \mathrm{~min}$.

of progenetic light sum, G. Hütt and I. Jaek reported on the 9th International Conference on Luminescence and Electron Spin Resonance Dating, Rome, 1999 that the effect of the short-wave region of the spectrum of the Sun on alkali feldspars is excitative, and bleaching at the same time (saving of the light sum takes place). Depending on the origin of the sample, the relative effectiveness of these two factors is very different (see Fig. 11). In any case, a balanced light sum, different from zero, remains in alkali feldspars during the accumulation process of the sediments.

Summing up the analysis of different dating protocols, we can conclude that besides single-grain procedures, which inevitably require statistical analysis of single results, it is necessary, when using the single-aliquot method, to make sure that the given aliquot includes adequately the sample being studied (deposit, its layer, etc.). It means that in any case a series of datings with different aliquots is needed. Hence, multi-aliquot protocols, which automatically give the average result for the given sample, are usable in every respect, especially when applying the variant with the stimulation impulses of short and weak intensity. In this case traps with high sensitivity to light, which were also most completely bleached during sedimentation, are automatically selected out.

A great number of papers published during the last decade, in which the above-described dating protocols are used for solving concrete geological problems, were not mentioned in this review. References to these works can be found in the above-cited generalizing articles. 


\section{CONCLUSIONS}

During the recent years great progress has been made in the study of the processes of energy accumulation and transformation in the minerals used as palaeodosimeters, in clarification of the characteristics of especially deep "dosimetric" traps and in deciphering the mechanism of their photoionization, as well as in measuring techniques and development of new apparatus used for dating. In spite of that further basic studies, justification and specification of concrete dating protocols are needed. New measuring methods (including new dose-sensitive characteristics) are to be searched for. Sensitive methods for dating very "young" samples, but also extending the time range of datings to the region of great ages $\left(t>10^{5}\right.$ years) are especially necessary.

\section{ACKNOWLEDGEMENTS}

This work was supported by the Estonian Science Foundation (grant No. 4049). Figures 1, 4, and 9 are reproduced with permission from Dr. K. V. R. Murthy, the editor of the Proceedings of International Symposium on Luminescence and Its Applications, ISLA-2000; Figs. 2, 5, and curve 2 in Fig. 1a with permission from NRC Research Press (Canada); and Figs. 3, 6, 7, and 8 with permission from Elsevier Science.

\section{REFERENCES}

Aitken, M. I. 1998. An Introduction to Optical Dating. Oxford Univ. Pr.

Alexander, C. S., Morris, M. F. \& McKeever, S. W. S. 1997. The time and wavelength response of phototransfered thermoluminescence in natural quartz. Radiat. Meas., 27, 153-159.

Bailey, R. M. 2000. The interpretation of quartz optically stimulated luminescence equivalent dose versus time plots. Radiat. Meas., 32, 129-140.

Bailey, R. M., Smith, B. W. \& Rhodes, E. I. 1997. Partial bleaching and decay from characteristics of quartz OSL. Radiat. Meas., 27, 123-136.

Bailiff, I. K. 1993. Measurements of the stimulation spectrum (1.2-1.7) eV for a specimen of potassium feldspars using a tuneable solid state laser. Radiat. Prot. Dosim., 47, 649-653.

Bailiff, I. K. \& Barnett, S. M. 1994. Characteristics of infrared-stimulated luminescence from a feldspars at low temperatures. Radiat. Meas., 23, 541-546.

Bailiff, I. K. \& Poolton, N. R. J. 1991. Studies of change transfer mechanism in feldspars. Nucl. Tracks Radiat. Meas., 18, 111-118.

Bøtter-Jensen, L. 2000. Developments of optically stimulated luminescence techniques. In Proceedings of International Symposium on Luminescence and Its Applications (Murthy, K. V. R. et al., eds.), pp. 73-78. Baroda, India.

Bøtter-Jensen, L., Duller, G. A. T. \& Poolton, N. R. J. 1994. Excitation emission spectrometry of stimulated luminescence from quartz and feldspars. Radiat. Meas., 23, 613-616.

Bøtter-Jensen, L., Bulur, E., Duller, G. A. T. \& Murray, A. S. 2000. Advances in luminescence instrument systems. Radiat. Meas., 32, 523-528. 
Bulur, E. 1996. An alternative technique for optically stimulated luminescence (OSL) experiment. Radiat. Meas., 26, 701-709.

Bulur, E. \& Göksu, H. Y. 1999. Infrared (IR) stimulated luminescence from feldspars with linearly increasing excitation light intensity. Radiat. Meas., 30, 505-512.

Bulur, E., Bøtter-Jensen, L. \& Murray, A. S. 2000. Optically stimulated luminescence from quartz measured using the linear modulation technique. Radiat. Meas., 32, 407-411.

Chougaonkar, M. P. 2000. Dose estimation by infrared stimulated luminescence at elevated temperatures using feldspar extracts and its implications in dating. In Abstracts of International Symposium Luminescence and Its Applications (Murthy, K. V. R. et al., eds.), p. 31. Baroda, India.

Clark, R. J. \& Sanderson, D. C. W. 1994. Characteristics of infrared-stimulated luminescence of feldspars and micas. Radiat. Meas., 23, 641-646.

Dietlefsen, C. \& Huntley, D. 1994. Optical excitation of trapped charges in quartz potassium feldspars and mixed silicates: the dependence on photon energy. Radiat. Meas., 23, 675-682.

Duller, G. A. T. 1991. Equivalent dose determination using single aliquots. Nucl. Tracks Radiat. Meas., 18, 371-378.

Duller, G. A. T. 1995. Luminescence dating using single aliquots: methods and applications. Radiat. Meas., 24, 217-226.

Duller, G. A. T. 2000. Dose distributions determined from measurements of single quartz grains. In Proceedings of International Symposium on Luminescence and Its Applications (Murthy, K. V. R. et al., eds.), pp. 78-86. Baroda, India.

Duller, G. A. T. \& Bøtter-Jensen, L. 1996. Comparison of optically stimulated luminescence signals from quartz using different stimulation wavelengths. Radiat. Meas., 26, 603-609.

Galloway, R. B. 1996. Equivalent dose determination using only one sample: alternative analysis of data obtained from infrared stimulation of feldspars. Radiat. Meas., 26, 103-106.

Godfrey-Smith, D. I. \& Cada, M. 1996. IR-stimulation spectroscopy of plagioclase and potassium feldspars and quartz. Radiat. Prot. Dosim., 66, 379-385.

Huntley, D. J., Godfrey-Smith, D. I. \& Thewalt, M. L. W. 1985. Optical dating of sediments. Nature, 313, 105-107.

Huntley, D. J., Short, M. A. \& Dunphy, K. 1996. Deep traps in quartz and their use for optical dating. Can. J. Phys., 74, 81-91.

Hütt, G. 1990. Radiation dosimetry and palaeodosimetry on the basis of recombination radioluminescence of some minerals and synthetic materials. DSc. Thesis, Institute of Geology, Tallinn.

Hütt, G. \& Jaek, I. 2000. Optically stimulated luminescence dosimetry and palaeodosimetry: study of physical basis. In Proceedings of International Symposium on Luminescence and Its Applications (Murthy, K. V. R. et al., eds.), pp. 94-103. Baroda, India.

Hütt, G., Jaek, I. \& Chonka, T. 1988. Optical dating: K-feldspars optical response stimulation spectra. Quat. Sci. Rev., 7, 381-387.

Hütt, G., Jaek, I. \& Streltsov, A. 1999. Study of deep traps in alkali feldspars and quartz by the optically stimulated afterglow. Radiat. Prot. Dosim., 84, 467-470.

Hütt, G., Jaek, I. \& Vasilchenko, V. 2001. Photoionization of radiation-induced traps in quartz and alkali feldspars. Appl. Radiat. Isot., 54, 175-182.

Jaek, I., Savikhin, F. \& Käämbre, H. 1974. LET dependence of TSL and TSEE yield as a basis for a fast neutron dosimetry method. In Proceedings of Fourth International Conference on Luminescence Dosimetry, pp. 565-574. Krakow.

Markey, B. G., Bøtter-Jensen, L., Poolton, N. R. J., Christiansen, H. E. \& Willumsen, F. 1996. A new sensitive system for measurements of thermally and optically stimulated luminescence. Radiat. Prot. Dosim., 66, 413-418.

McKeever, S. W. S. \& Chen, R. 1997. Luminescence models. Radiat. Meas., 27, 625-661.

McKeever, S. W. S., Bøtter-Jensen, L., Agersnap Larsen, N. \& Duller, G. A. T. 1997. Temperature dependence of OSL decay curves: experimental and theoretical aspects. Radiat. Meas., 27, $161-170$. 
Murray, A. S. 2000. Single aliquot protocols in luminescence dating. In Proceedings of International Symposium on Luminescence and Its Applications (Murthy, K. V. R. et al., eds.), pp. 103-108. Baroda, India.

Murray, A. S. \& Olley, J. M. 1999. Determining sedimentation rates using luminescence dating. GeoResearch Forum, Vol. 5. Trans. Tech. Publications, Switzerland, 121-144.

Murray, A. S. \& Roberts, R. G. 1997. Determining the burial time of single grains of quartz using optically stimulated luminescence. Earth Planet. Sci. Lett., 152, 163-180.

Murray, A. S. \& Wintle, A. G. 1998. Factors controlling the shape of the OSL decay curve in quartz. Radiat. Meas., 29, 65-79.

Murray, A. S. \& Wintle, A. G. 2000. Luminescence dating of quartz using an improved singlealiquot regenerative-dose protocol. Radiat. Meas., 32, 57-73.

Murray, A. S., Roberts, R. G. \& Wintle, A. G. 1997. Equivalent dose measurement using a single aliquot of quartz. Radiat. Meas., 27, 171-184.

Olley, J. M., Caitcheon, G. G. \& Roberts, R. G. 1999. The origin of dose distribution in fluvial sediments and the prospect of dating single grains from fluvial deposits using optically stimulated luminescence. Radiat. Meas., 30, 207-217.

Poolton, N. R. J., Bøtter-Jensen, L. \& Johnsen, O. 1995. Thermooptical properties of optically stimulated luminescence in feldspars. Radiat. Meas., 24, 531-534.

Rieser, U., Hütt, G., Krbetschek, M. R. \& Stolz, W. 1997. Feldspars IR-OSL emission spectra at high and low temperatures. Radiat. Meas., 27, 273-278.

Smith, B. W. \& Rhodes, E. I. 1994. Charge movements in quartz and their relevance to optical dating. Radiat. Meas., 23, 329-333.

Spooner, N. A. 1994. On the optical dating signal from quartz. Radiat. Meas., 23, 593-600.

Visosecas, R. 1993. Tunneling radiative recombination in K-feldspar sanidine. Nucl. Tracks Radiat. Meas., 25, 175-178.

Visosecas, R., Spooner, N. A., Zink, A. \& Blanc, P. 1994. Tunnel fading and infrared emission in thermoluminescence of feldspar. Radiat. Meas., 23, 377-385.

Wintle, A. 1997. Luminescence dating: laboratory procedures and methods. Radiat. Meas., 27, 769817.

Wintle, A. 2000. Monitoring luminescence sensitivity changes in quartz in dating processes. In Proceedings of International Symposium on Luminescence and Its Applications (Murthy, K. V. R. et al., eds.), pp. 64-73. Baroda, India.

Wintle, A. G. \& Murray, A. S. 1997. The relationship between quartz thermoluminescence and optically stimulated luminescence. Radiat. Meas., 27, 611-624.

\section{PROGRESS LUMINESTSENTSDATEERIMISE VALLAS: OPTILISELT STIMULEERITUD LUMINESTSENTSI PROTSEDUURID JA NENDE FÜÜSIKALISED ALUSED}

\section{Galina HÜTT ja Ivar JAEK}

On antud ülevaade looduslike paleodosimeetritena tuntud kvartsis ja leelispäevakivides toimuvate energiasalvestus- ja transformatsiooniprotsesside uurimisel viimase kümne aasta jooksul saavutatust ning näidatud, kuidas saadud tulemused aitasid laiendada optilise dateerimise rakendusvõimalusi: on leitud efektiivsemaid stimulatsiooni spektraalpiirkondi ning valitud optimaalseid stimuleerivate impulsside kestusi ja võimsusi. On analüüsitud uute optilise dateerimise mõõtmisprotseduuride (protokollide) tugevaid ja nõrku külgi, pidades silmas 
esmajoones üksikkatsendi ja üksiktera protseduure. On tutvustatud vastavat uut, suure tundlikkusega aparatuuri. Esitatust nähtub, et stimuleerivate impulsside parameetrite mõistlikul valikul on seni laialt kasutatav mitme katsendi meetod täiesti konkurentsivõimeline uusimate meetoditega võrreldes.

\title{
ПРОГРЕСС В ОБЛАСТИ ЛЮМИНЕСЦЕНТНОГО ДАТИРОВАНИЯ: ПРОЦЕДУРЫ НА ОСНОВЕ ОПТИЧЕСКОЙ СТИМУЛЯЦИИ ЛЮМИНЕСЦЕНЦИИ И ИХ ФИЗИЧЕСКАЯ ПРИРОДА
}

\author{
Галина ХЮТТ и Ивар ЯЭК
}

В виде обзора представлены результаты исследования процессов аккумуляции и трансформации энергии в двух природных дозиметрах в кварце и полевых шпатах - за последнее десятилетие. Показано, как путем определения наиболее эффективных спектральных областей для стимуляции и выбора оптимальных длительностей и мощностей стимулирующих импульсов удается значительно расширить возможности оптического датирования. Проанализированы сильные и слабые стороны предложенных процедур. Имеются в виду процедуры одной порции и одного зерна. Описана новая высокочувствительная аппаратура. Оказывается, при разумном выборе параметров стимулирующих импульсов широко практикуемый ныне многопорционный метод вполне конкурентноспособен с другими современными методами. 